\title{
Adjuvant celecoxib and lanreotide following transarterial chemoembolisation for unresectable hepatocellular carcinoma: a randomized pilot study
}

\author{
Huan Tong ${ }^{1}$, Bo Wei ${ }^{1}$, Shuang Chen ${ }^{1}$, Yong-Mei Xie ${ }^{2}$, Ming-Guang Zhang ${ }^{1}$, Lin-Hao \\ Zhang $^{1}$, Zhi-Yin Huang ${ }^{1}$ and Cheng-Wei Tang ${ }^{1}$ \\ ${ }^{1}$ Department of Gastroenterology, West China Hospital, Sichuan University, Chengdu, China \\ 2 Department of Pediatrics, West China Second University Hospital, Sichuan University, Chengdu, China \\ Correspondence to: Cheng-Wei Tang, email: shcacdmed@163.com \\ Keywords: hepatocellular carcinoma, transarterial chemoembolisation, celecoxib, lanreotide, survival \\ Received: October 07, $2016 \quad$ Accepted: February 15, $2017 \quad$ Published: February 24, 2017
}

Copyright: Tong et al. This is an open-access article distributed under the terms of the Creative Commons Attribution License 3.0 (CC BY 3.0), which permits unrestricted use, distribution, and reproduction in any medium, provided the original author and source are credited.

\section{ABSTRACT}

Recurrence of hepatocellular carcinoma (HCC) after transarterial chemoembolisation (TACE) is common due to neoangiogenesis. Cyclooxygenase-2 inhibitors and somatostatin analogues were reported to inhibit tumour angiogenesis. The pilot randomized controlled trial was aimed to prospectively evaluate the protocol of TACE combined with celecoxib and lanreotide (TACE $+C+L$ ) in patients with unresectable and advanced HCC. A total of 71 patients with HCC were enrolled and randomly assigned to either TACE $(n=35)$ or TACE $+C+L(n=36)$ group. Overall survival, disease control rate (DCR), and adverse events were assessed during a 3-year follow-up period. The median overall survival of the TACE $+C+L$ group (15.0 months) was doubled compared to that of TACE group ( 7.5 months), $p=0.012$. DCR of the TACE $+C+L$ group was significantly higher than that of the TACE group either at 6 months $(72.2 \%$ vs $42.9 \%, p=0.012)$ or at 12 months $(61.1 \%$ vs $28.6 \%, p=$ 0.006 ). The median overall survivals (13 months vs 4.5 months, $p=0.013$ ) and DCR at 12 months $(50 \%$ vs $13.6 \%, p=0.008)$ of patients with advanced HCC in TACE $+C+L$ groups were significantly higher than those in TACE group. No significant difference of adverse events was observed between the two groups. The occurrence of post-embolisation syndrome in TACE $+C+L$ group was significantly lower than that in TACE group $(16.7 \%$ vs $60.0 \%, p=0.001)$. In conclusion, the regimen of TACE $+C+L$ prolonged overall survival, enhanced tumour response, reduced post-embolisation syndrome and was well-tolerable in the patients with unresectable HCC. It may be more beneficial for advanced HCC.

\section{INTRODUCTION}

As most of patients with hepatocellular carcinoma (HCC) are not suitable candidates for curative treatment, palliative treatment remains as the only available option. Transarterial chemoembolisation (TACE) is considered to be the first line therapy in patients with unresectable HCC of Barcelona Clinic Liver Cancer (BCLC) classified intermediate-stage (BCLC stage B) [1]. Despite the survival benefit of TACE in patients with intermediate
HCC, TACE is a palliative treatment that does not result in complete tumor necrosis. Recurrence of HCC after TACE is common due to neoangiogenesis [2]. The neoangiogenesis of HCC after TACE has been linked to the increased expression of hypoxia-inducible factors or vascular endothelial growth factor (VEGF) in the residual surviving cancerous tissue $[3,4]$. Theoretically, combination of TACE and antiangiogenic agents would be more feasible. However, combination strategies of TACE and systemic therapies (sorafenib or bevacizumab) have not resulted in clinical benefit $[5,6]$. A meta-analysis 
that included the combination of different loco-regional therapies, such as TACE and radiofrequency ablation, produced some inconclusive results on TACE [7].

Cyclooxygenase (COX) is a key rate-limiting enzyme for the synthesis of prostaglandin. COX-2, an isoenzyme of COX, plays an essential role in the development of HCC. Over-expression of COX-2 has been considered as related to hepato-carcinogenesis and angiogenesis [8, 9]. Therefore, treatment with COX-2 inhibitors, such as celecoxib, might be promising in HCC. Previous studies have suggested that COX-2 inhibitors could inhibit the growth of HCC either in animal models or in patients $[10,11]$.

In addition, somatostatin is a widely distributed neuropeptide with multiple physiological functions, including immune regulation and tumour suppression. Overexpression of somatostatin receptors (SSTRs) has also been identified in HCC $[12,13]$. Our previous experiment showed that somatostatin analogue (SSTA), such as octreotide and pasireotide, caused substantial necrosis of HCC xenografts in vivo [14]. Recently, we observed that pasireotide, combined with celecoxib, prolonged the survival in nude mice [15]. Moreover, combination of the above two types of non-cytotoxic agents displayed a synergistic inhibitory role on the growth or metastasis of the liver neoplasm in rabbits of post-TACE $[16,17]$. However, the potential effects of the multi-modality protocol on the survival of patients who underwent TACE have not been assessed. As octreotide has a short half-life, lanreotide, the second SSTA available in the market, binds to the same receptors as octreotide with a higher affinity to SSTR-2, -5 , and bears more advantages in the long-term therapy of HCC compared with octreotide. This prospective randomized controlled trial (RCT) was aimed to evaluate the overall survival, tumour response, disease control rate (DCR) and adverse events of TACE plus celecoxib and lanreotide in the patients with unresectable HCC.

\section{PATIENTS AND METHODS}

\section{Patients}

This RCT was conducted from October 2008 to June 2013 in West China Hospital, according to the protocol which conformed to the ethical guidelines of the Declaration of Helsinki 1975 and was approved by Chinese Ethics Committee of Registering Clinical Trials. The recruitment of participants ended in June 2010. The trial was registered in the Chinese Clinical Trial Registry (http://www.chictr.org/cn/; registration number: ChiCTRTRC-08000191). Written informed consent was obtained from each patient.
Male or female patients between the ages of 18-75 years with a confirmed diagnosis of unresectable HCC were the eligible patients for this study. Patients with BCLC stage B-C [18] were recruited. Exclusion criteria were listed as below: decompensated liver disease (ChildPugh grade B8-C15); active gastrointestinal bleeding; hepatic encephalopathy; extrahepatic metastasis; severe portosystemic shunt or hepatofugal blood flow; impaired clotting tests (platelet count $<50 \times 10^{9} / \mathrm{L}$ or prothrombin activity $<50 \%$ ); renal dysfunction; other severe systemic diseases; pregnant or breast feeding women and hyperallergy to drugs used in this study or to sulfanilamide.

\section{Grouping and intervention}

Eligible patients were consecutively included and assigned to either TACE group or TACE + celecoxib+lanreotide $(\mathrm{TACE}+\mathrm{C}+\mathrm{L})$ group, by using computer-generated randomization numbers. All clinical data were evaluated through history taking and clinical laboratory tests. Prior to the TACE procedure, liver function of each patient was evaluated according to the Child-Pugh grade. The general status of patients was evaluated using Karnofsky performance score (KPS). The patients were also stratified according to the BCLC stage for further analysis.

The schedule of TACE session was arranged as: baseline, 3 consecutive courses with interval of 2 months, then once per 3 months until the end of follow-up. Routine TACE procedure mainly included catheterization of flexible microcatheter (Terumo, Tokyo, Japan), injection of emulsion mixture with 20mg doxorubicin (Main Luck, Shenzhen, China) in 10ml iodized oil (Guerbet, Roissy $\mathrm{CdG}$ cedex, France) and embolisation with granules of absorbable gelatin sponge (Xiang'en, Nanchang, China).

Oral celecoxib $\left(\right.$ Celebrex $^{\circledR}$, Pfizer, New York, USA) $200 \mathrm{mg}$ was given twice a day for 3 months, and afterwards $200 \mathrm{mg}$ once daily until the end of followup. Lanreotide (Somatuline LA ${ }^{\circledR}$, IPSEN, Paris, France) was administered as $40 \mathrm{mg}$ intramuscular injections once monthly for 3 circles, then once per 2 months for 3 circles, and thereafter once per 3 months until the end of followup. Oral celecoxib $200 \mathrm{mg}$ twice daily or lanreotide 40 $\mathrm{mg}$ intramuscular injections were initially administered a week prior to the first course of TACE.

TACE, administration of celecoxib and lanreotide would be discontinued if there were following settings: tumour response of progressive disease (PD) for $>6$ months assessed by modified Response Evaluation Criteria in Solid Tumors (mRECIST) [19], liver function of ChildPugh grade B8-C15, KPS $<70$, or any other item of the exclusion criteria. TACE would be withheld when viable tumour foci were not visible on imaging. 


\section{Follow-up}

The clinical course, DCR, tumour response and deaths were regularly documented per 3 months during the follow-up period of 3 years. Tumour response was assessed by contrast-enhanced ultrasound or spiral computed tomography, according to mRECIST [19], and two evaluators studied the imaging independently and were blinded to treatment assignment. Tumour response was defined into four grades: complete response (CR), partial response (PR), stable disease (SD), and PD. DCR was calculated as: $(\mathrm{CR}+\mathrm{PR}+\mathrm{SD}) /$ total patient number $\times$ $100 \%$. Metastases were assessed by bone scintigraphy and cerebral MRI on the basis of the symptoms of patients. Endoscopy was performed when gastrointestinal bleeding was indicated. The adverse events were documented using Common Terminology Criteria for Adverse Events (CTCAE) version 3.0 at every visit [20]. The postembolisation syndrome (PES) was set as a constellation of symptoms consisting of fevers, unremitting nausea, general malaise, loss of appetite, and variable abdominal pain following the TACE procedure.

\section{Efficacy outcomes}

Overall survival was defined as the primary outcomes. The secondary outcomes included the following: tumour response, DCR, KPS and adverse events.

\section{Sample size calculation and statistical analysis}

The sample size calculation was based on the assumption that there would be a median overall survival increase of 6 months from TACE treatment alone. A sample size of 28 cases in each group would provide a $90 \%$ power to estimate the overall survival improvement at $5 \%$ level of significance in this study. Taking into account a possibility of loss to follow-up of $20 \%, 35$ cases were required in each group for this study.

Survival analysis was performed with the log-rank test. Cox proportional hazard regression was utilized to determine hazard ratios (HRs) of factors on survival. Univariate analysis and multivariate analysis were deployed to determine the influence of probable risk factors on survival. Similarly, the odds ratios (ORs) of factors on PES were calculated by logistic regression. Chi-square test was used for evaluating tumour responses. Baseline characteristics were tested using the chi-square or student's test, depending on the type of data. All the statistical work was conducted with SPSS 13.0 software (IBM, Chicago, USA).

\section{RESULTS}

\section{Patient characteristics and compliance}

A total of 129 unresectable HCC patients were assessed for eligibility. Finally, 71 patients were enrolled sequentially, and one patient was lost during the follow-up (Figure 1). The baseline characteristics of two groups were in parallel (Table 1). Infection of hepatitis B virus was the major underlying liver disease of patients in both groups. The patients with BCLC stage $\mathrm{C}$ in the two groups were 2 -fold of BCLC stage B. TACE group underwent $4.7 \pm 4.0$ sessions of TACE. In contrast, $7.5 \pm 4.5$ sessions of TACE were performed in TACE $+\mathrm{C}+\mathrm{L}$ group, about 1.6-fold of TACE group.

\section{Overall survival}

The median overall survival of TACE $+\mathrm{C}+\mathrm{L}$ group increased to 2-fold compared with TACE group (Table 2). The accumulated survival rate of patients in TACE $+\mathrm{C}+\mathrm{L}$ group at 12 months $(66.7 \%)$ was enhanced by $26.7 \%$, compared with TACE group (40\%), and the $24-$ and 36 -month survival rates of TACE $+\mathrm{C}+\mathrm{L}$ group (24-month, $30.6 \%$; 36-month, $25 \%$ ) were over 2 -fold higher than those of TACE group (24-month, 14.3\%; 36-month, $8.6 \%$ ). The median overall survival $(\mathrm{TACE}+\mathrm{C}+\mathrm{L} v s$ TACE 13 months $v s 4.5$ months, $p=0.013$ ) and DCR at 12 month (TACE $+\mathrm{C}+\mathrm{L} v s$ TACE $50 \% v s 13.6 \%, p=0.008)$ of patients with $\mathrm{BCLC}$ stage $\mathrm{C}$ in $\mathrm{TACE}+\mathrm{C}+\mathrm{L}$ group were significantly higher than those in TACE group. KPSs in $\mathrm{TACE}+\mathrm{C}+\mathrm{L}$ group both at 6 months and at 12 months were significantly higher than those in TACE group (Table 2). The constituent ratio of Child-Pugh grade B in $\mathrm{TACE}+\mathrm{C}+\mathrm{L}$ group at 12 months was significantly lower than that at baseline (at 12 months vs baseline 9/24vs $23 / 36, p=0.045$ ). In contrast to it, TACE intervention alone did not improve the constituent ratio of Child-Pugh grade B at 12 month (at 12 months $v s$ baseline 9/14 vs $24 / 35, p=0.773)$. In addition, the rates of various causes of death were similar between two groups (Table 3).

Univariate and multivariate analyses respectively showed that the HRs of probable risk factors on survival were as follows: BCLC stage 0.454 (95\% CI 0.291 to $0.708, p=0.001), 0.429$ (95\% CI 0.267 to $0.689, p<0.001)$; KPS 0.941 (95\% CI 0.913 to 0.971 , $p<0.001), 0.948$ (95\% CI 0.917 to $0.980, p=0.001$ ); celecoxib+lanreotide 0.534 (95\% CI 0.321 to $0.888, p=$ $0.016), 0.485$ (95\% CI 0.283 to $0.831, p=0.008)$. The HRs of age, gender and AFP level did not show significant impacts on the survival of patients underwent TACE, $p>$ 0.05 . 


\section{Tumour response}

No CR was observed in two groups. SD was the main tumour response (Table 2). DCR of the TACE $+\mathrm{C}+\mathrm{L}$ group was significantly higher than that of the TACE group at either 6 months or at 12 months (Table 2). The significant difference was owing to the great enhancement of DCR in patients with BCLC stage C. DCRs of patients with $\mathrm{BCLC}$ stage $\mathrm{C}$ in $\mathrm{TACE}+\mathrm{C}+\mathrm{L}$ group increased to 2.1- and 3.7-fold of TACE group at 6 and 12 months, respectively.

\section{Adverse events}

No significant difference of adverse events, including nonvariceal gastrointestinal hemorrhage, ulcer and liver dysfunction/failure, was observed between the two groups, except for abdominal bloating (Table 3). The several liver failure-related deaths in each group occurred after TACE, celecoxib and lanreotide were discontinued because of PD over 6 months. Also, no severe and fatal adverse events associated with celecoxib and lanreotide were observed in $\mathrm{TACE}+\mathrm{C}+\mathrm{L}$ group .

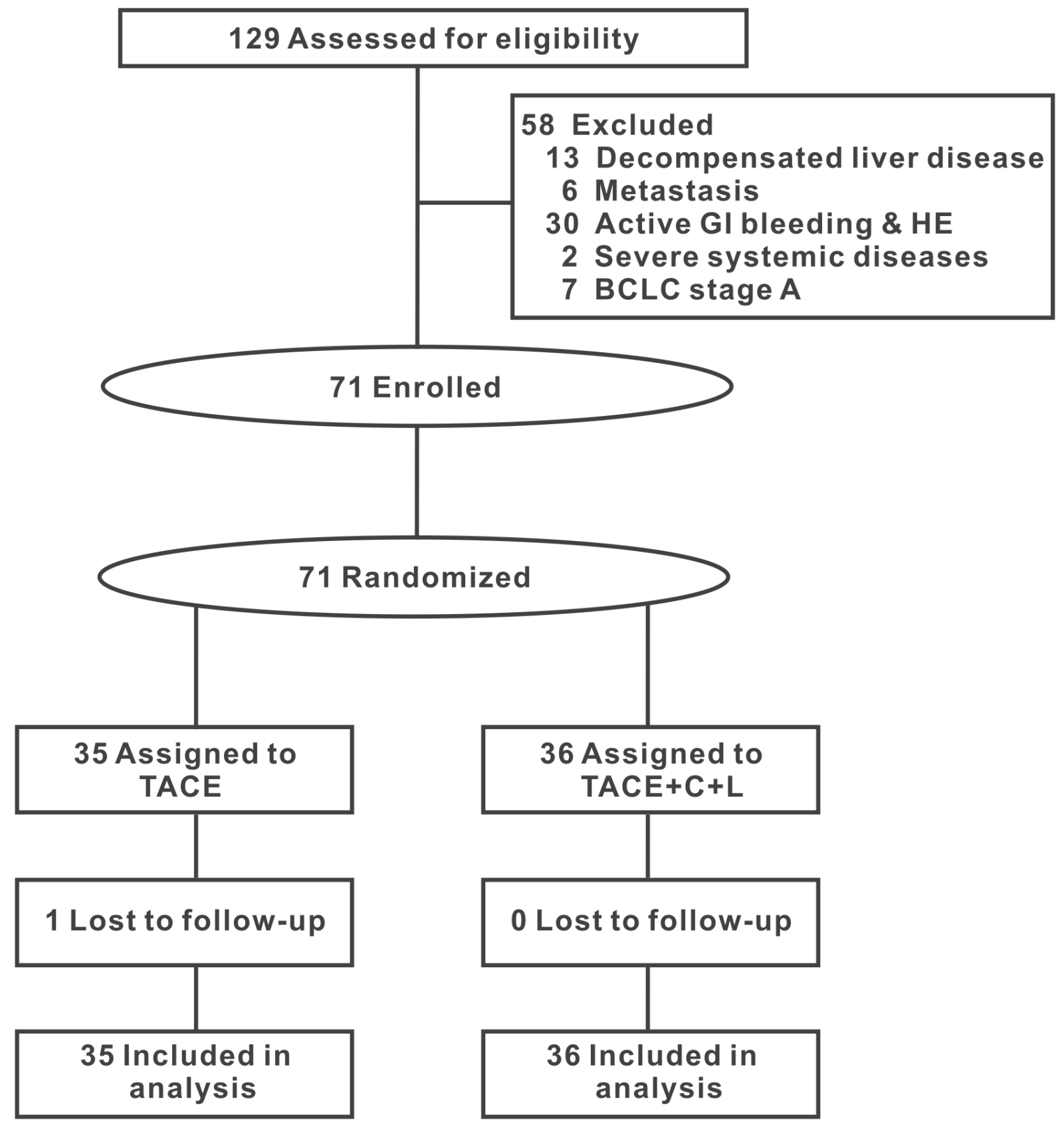

Figure 1: Flow of participants. BCLC: Barcelona Clinic Liver Cancer; GI: gastrointestinal; HE: hepatic encephalopathy. 
Table 1: Baseline characteristics

\begin{tabular}{|c|c|c|c|}
\hline & $\begin{array}{l}\text { TACE } \\
(n=35)\end{array}$ & $\begin{array}{l}\text { TACE+C+L } \\
(n=36)\end{array}$ & $P$ value \\
\hline Age (mean \pm SD, years) & $55.4 \pm 12.7$ & $56.7 \pm 12.4$ & 0.664 \\
\hline Gender (male/female, $n$ ) & $29 / 6$ & $31 / 5$ & 0.705 \\
\hline \multicolumn{4}{|l|}{ Underlying liver disease ( $n$ ) } \\
\hline Hepatitis B virus & 24 & 23 & \multirow{5}{*}{0.828} \\
\hline Hepatitis $\mathrm{C}$ virus & 0 & 1 & \\
\hline Alcohol & 3 & 2 & \\
\hline Mixed & 6 & 8 & \\
\hline Others & 2 & 2 & \\
\hline With/without cirrhosis & $30 / 5$ & $27 / 9$ & 0.257 \\
\hline Child-Pugh grade A/B (n) & $11 / 24$ & $13 / 23$ & 0.677 \\
\hline $\operatorname{AFP}(<400 />400 \mathrm{ng} / \mathrm{ml}, n)$ & $16 / 19$ & $18 / 18$ & 0.718 \\
\hline BCLC stage B/C (n) & $13 / 22$ & $10 / 26$ & 0.399 \\
\hline KPS (Mean \pm SD) & $76.6 \pm 7.3$ & $78.1 \pm 8.6$ & 0.434 \\
\hline Abdominal pain (n) & 25 & 28 & 0.539 \\
\hline Constitutional syndrome $(n)^{\mathrm{a}}$ & 31 & 30 & 0.735 \\
\hline
\end{tabular}

${ }^{a}$ Constitutional syndrome is characterized by the presence of asthenia, anorexia, malaise and weight loss. AFP: alpha fetoprotein; BCLC: Barcelona Clinic Liver Cancer; KPS: Karnofsky performance score.

Table 2: Overall survival, tumour response and life quality

\begin{tabular}{|c|c|c|c|}
\hline & TACE & $\mathbf{T A C E}+\mathbf{C}+\mathbf{L}$ & $P$ value \\
\hline \multicolumn{4}{|c|}{ Overall survival (Median, 95\% CI, months) } \\
\hline \multirow{2}{*}{ All patients } & $n=35$ & $n=36$ & \\
\hline & $7.5(2.4-12.6)$ & $15.0(12.1-17.9)$ & 0.012 \\
\hline \multirow[t]{2}{*}{ BCLC stage B } & $n=13$ & $n=10$ & \\
\hline & $12.0(7.9-16.1)$ & $36.0(11.0-61.1)$ & 0.084 \\
\hline \multirow[t]{2}{*}{ BCLC stage $\mathrm{C}$} & $n=22$ & $n=26$ & \\
\hline & $4.5(1.7-7.3)$ & $13.0(8.0-18.0)$ & 0.013 \\
\hline \multicolumn{4}{|c|}{ KPS of all patients (Mean \pm SD) } \\
\hline 6-month & $75.5 \pm 7.6$ & $81.3 \pm 8.8$ & 0.020 \\
\hline 12-month & $70.7 \pm 6.2$ & $81.3 \pm 9.9$ & $<0.001$ \\
\hline \multicolumn{4}{|c|}{ Tumour response (CR/PR/SD/PD, n) } \\
\hline \multicolumn{4}{|c|}{\begin{tabular}{l|l}
6 -month & \\
\end{tabular}} \\
\hline All patients & $0 / 6 / 9 / 5$ & $0 / 17 / 9 / 5$ & 0.220 \\
\hline BCLC stage B & $0 / 4 / 4 / 1$ & $0 / 7 / 2 / 0$ & 0.289 \\
\hline BCLC stage $\mathrm{C}$ & $0 / 2 / 5 / 4$ & $0 / 10 / 7 / 5$ & 0.305 \\
\hline \multicolumn{4}{|l|}{ 12-month } \\
\hline All patients & $0 / 3 / 7 / 4$ & $0 / 11 / 11 / 2$ & 0.153 \\
\hline BCLC stage B & $0 / 3 / 4 / 1$ & $0 / 5 / 4 / 0$ & 0.485 \\
\hline BCLC stage C & $0 / 0 / 3 / 3$ & $0 / 6 / 7 / 2$ & 0.089 \\
\hline \multicolumn{4}{|l|}{ DCR (\%) } \\
\hline \multicolumn{4}{|l|}{ 6-month } \\
\hline All patients & 42.9 & 72.2 & 0.012 \\
\hline BCLC stage B & 61.5 & 90.0 & 0.179 \\
\hline BCLC stage C & 31.8 & 65.4 & 0.020 \\
\hline \multicolumn{4}{|l|}{ 12-month } \\
\hline All patients & 28.6 & 61.1 & 0.006 \\
\hline BCLC stage B & 53.8 & 90.0 & 0.089 \\
\hline BCLC stage C & 13.6 & 50.0 & 0.008 \\
\hline
\end{tabular}

BCLC: Barcelona Clinic Liver Cancer; CR: complete response; DCR: disease control rate; KPS: Karnofsky performance score; PD: progressive disease; PR: partial response; SD: stable disease. 
Table 3: Adverse events and cause of death

\begin{tabular}{|l|c|c|c|}
\hline & $\begin{array}{l}\text { TACE } \\
(\boldsymbol{n}=\mathbf{3 5})\end{array}$ & $\begin{array}{l}\text { TACE+C+L } \\
(\boldsymbol{n}=\mathbf{3 6})\end{array}$ & P value \\
\hline Adverse events (n) & & & \\
\hline Abdominal bloating (Grade 1) & 12 & 5 & 0.044 \\
\hline Anorexia (Grade 1) & 9 & 5 & 0.051 \\
\hline Diarrhea (Grade 1) & 3 & 3 & 0.710 \\
\hline Fever (Grade 1) & 7 & $0 / 1$ & 0.189 \\
\hline $\begin{array}{l}\text { Hemorrhage, GI } \\
\text { (nonvariceal, Grade 1/2) }\end{array}$ & $0 / 0$ & $0 / 0$ & 1 \\
\hline Liver dysfunction / failure (Grade 2/3)* & $4 / 1$ & $3 / 0$ & 0.063 \\
\hline Nausea (Grade 1/2) & $7 / 2$ & $1 / 0$ & 0.157 \\
\hline Pain (Grade 1/2) & $2 / 3$ & 1 & 1 \\
\hline Renal failure (Grade 3) & 1 & $1 / 0$ & 1 \\
\hline Ulcer (Grade 1/2) & $0 / 0$ & $1 / 1$ & 0.218 \\
\hline Vomiting (Grade 1/2) & $5 / 1$ & & \\
\hline Cause of death (n) & & 11 & 0.282 \\
\hline Liver failureb & 15 & 7 & 0.953 \\
\hline VUGIB & 7 & 2 & 0.429 \\
\hline HRS & 4 & 3 & 0.710 \\
\hline Tumour rupture & 4 & 4 & 0.357 \\
\hline Pneumonia & 1 & & \\
\hline
\end{tabular}

a Adverse event grade 1 for liver dysfunction / failure and grade 1 and 2 for renal failure are not included in CTCAE version $3 \cdot 0$.

${ }^{\mathrm{b}}$ Deaths occur after the discontinuation of treatment for tumour response of progressive disease. The liver function does not deteriorate while treatment is discontinued.

HRS: hepatorenal syndrome; VUGIB: variceal upper gastrointestinal bleeding.

The occurrence of PES in TACE $+\mathrm{C}+\mathrm{L}$ group was significantly lower than that in TACE group (TACE $+\mathrm{C}+\mathrm{L}$ vs TACE, $16.7 \%$ vs $60.0 \%, p=0.001)$. Univariate and multivariate logistic regressions respectively showed that the ORs for probable factors on PES were as follows: celecoxib+lanreotide 0.106 (95\% CI 0.033 to $0.338, p<$ $0.001), 0.011$ (95\% CI 0.001 to $0.118, p<0.001)$; age 2.212 (95\% CI 1.233 to $3.968, p=0.008), 3.250(95 \%$ CI 1.529 to $6.910, p=0.002)$; AFP 0.427 (95\% CI 0.191 to $0.954, p=0.038), 0.313(95 \%$ CI 0.114 to $0.861, p=$ 0.024). The ORs of gender, BCLC stage, KPS and TACE sessions did not show significant impacts on PES of patients underwent TACE, $p>0.05$.

\section{DISCUSSION}

The global burden of HCC is increasing. RCTs to test new treatments in the adjuvant setting and to test

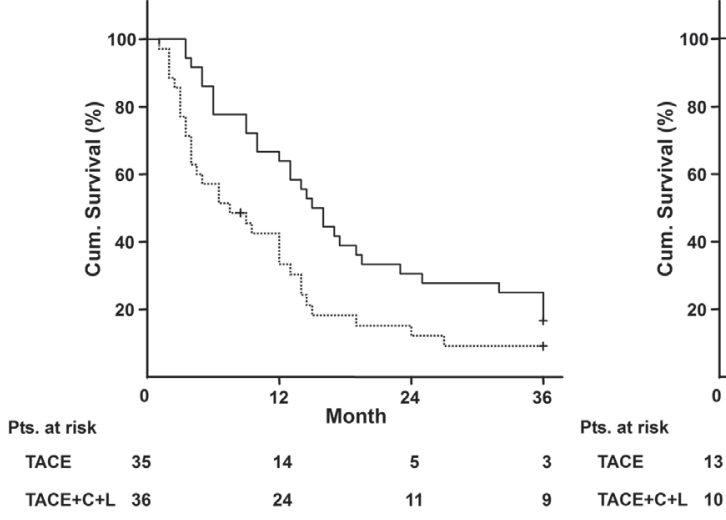

(A)

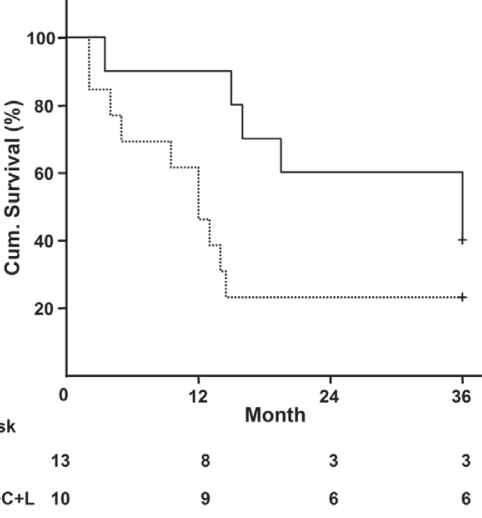

(B)

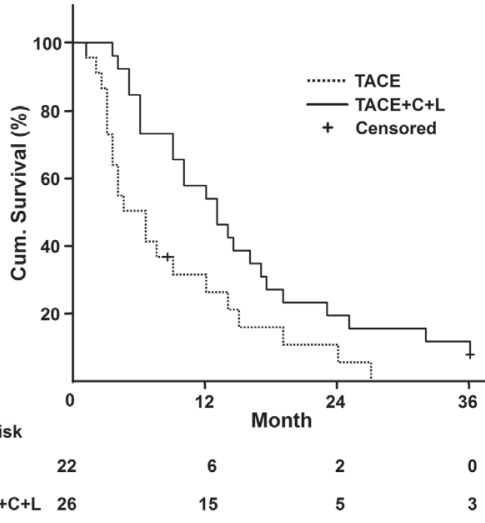

(C)

Figure 2: Evaluation of survival. A. All patients; B. Patients with BCLC stage B; C. Patients with BCLC stage C. BCLC: Barcelona Clinic Liver Cancer; Cum.: Cumulative; Pts.: patients. 
combination therapies in intermediate and advanced HCC are main medical needs for HCC. However, none of the combination therapies with chemoembolisation has shown additive outcome advantages. This is the first clinical trial of a systemic utilization of celecoxib and lanreotide in combination with TACE $(\mathrm{TACE}+\mathrm{C}+\mathrm{L})$. Compared with TACE group, TACE $+\mathrm{C}+\mathrm{L}$ group significantly increased the median overall survival by 7.5 months (from 7.5 months to 15 months). Among the probable risk factors on survival, BCLC stage, KPS and celecoxib+lanreotide showed significant HRs. The 2-fold higher overall survival in $\mathrm{TACE}+\mathrm{C}+\mathrm{L}$ group indicated the adjuvant efficacy of celecoxib and lanreotide when the baselines of BCLC stage and KPS were in parallel.

The survival of HCC patients is rationally related to tumour progress and cirrhotic improvement. DCRs of $\mathrm{TACE}+\mathrm{C}+\mathrm{L}$ group were significantly higher than that of TACE group at both 6 months and 12 months, suggesting a better tumour response for $\mathrm{TACE}+\mathrm{C}+\mathrm{L}$ regimen. Such a synergistic inhibitory role in HCC treatment is supported by the basis of our previous experiment of rabbits with hepatic VX2 allografts. In the animal model, TACE plus octreotide and celecoxib synergistically prolonged the survival through antiangiogenesis, induction of allograft capsule formation, and inhibition of growth and metastasis of the tumour [16, 17]. Although protocol of either TACE+lanreotide/octreotide or TACE+celecoxib ever showed a little survival benefit in our previous animal experiment or preclinical test, their efficacies were inferior to that of TACE+lanreotide/octreotide+celecoxib. The potential mechanisms behind the regimen may due to the inactivation of $\mathrm{p}$-ERK - HIF-1 $\alpha / \mathrm{VEGF}$, endothelial nitric oxide synthase, MAPK - ERK, JNK - p38, and TGF- $\beta 1 /$ Smads integrated signaling pathways, which are involved in the cross-talk of COX-2 and SST signal transduction. The synergistic outcome of SSTA and COX-2 inhibitor led to a higher efficiency in inhibition of p-ERK, HIF-1 $\alpha$, VEGF and angiogenesis than either one alone [15-17, 2123].

As the tumour microenvironment has a crucial role in the natural history of $\mathrm{HCC}$, there is a strong rationale for anti-inflammation and reduction of protumorigenic stroma. About $80 \%$ of patients in this study had concomitant cirrhosis. Besides chronic inflammation plays a stimulatory role in the fibrosis, proinflammatory conditions promote HCC onset and progression via activation of Wnt and EGFR signaling pathways [24]. Celecoxib and octreotide may ameliorate liver fibrosis in the cirrhotic rats model via the inhibition of intrahepatic and extrahepatic inflammation, and angiogenesis [23, $25,26]$. Also, celecoxib could inhibit the epithelialmesenchymal transition of hepatocytes by reduction of intrahepatic inflammation, preservation of normal basement matrix and inhibition of TGF- $\beta 1 /$ Smad pathway [27]. Besides anti-fibrosis, the pharmacological effect of lanreotide on portal hypertension through reduction of blood volumes in the portal system allows sufficient perfusion in vital organs, reducing the risk of ascites and the hepatorenal syndrome [28]. Therefore, the combination of celecoxib and lanreotide may be helpful to target the microenvironment in HCC. The greatly enhanced KPS and decreased ratio of Child-Pugh grade $\mathrm{B}$ in $\mathrm{TACE}+\mathrm{C}+\mathrm{L}$ group suggested the improvement of liver cirrhosis.

The short half-life period $(8 \mathrm{~h})$ of octreotide becomes a drawback in the long term treatment of HCC. As a member of somatostatin analogue family, lanreotide in a slow release formulation (7-14 d) was originally indicated for acromegaly and gastroenteropancreatic neuroendocrine tumors [29]. The administered schedule in this setting is recommended as $40 \mathrm{mg}$ intramuscularly every 2 weeks. Although there are few case reports on the application of lanreotide in HCC treatment, no recommendation of dosage or interval was available for lanreotide (Somatuline LA ${ }^{\circledR}$ ) in HCC treatment [30, 31]. In this study, the down-stair interval of lanreotide injection was on the basis of following considerations: 1) Conventional injection interval of lanreotide was on the basis of antisecretory efficacy of its pharmacokinetic profile. This might be unfavorable interval of antitumoral effects on account of complicated mechanisms. 2) A rational administration interval of lanreotide during the prolonged HCC treatment should consider the maintenance of sensitivity of SSTRs and reduction of adverse events. Persistent administration of high dosage of SSTA may induce receptor internalization, which renders the target cell insensitive to SSTA [32, 33]. Although lanreotide was tolerable in most of clinical studies less than 1 year, diarrhea and gallstone formation were identified as the main adverse events. Impairment of glucose homeostasis was a regular phenomenon. Our preclinical tests with several administration interval of lanreotide were much helpful to set the regimen of lanreotide for the pilot RCT.

The BCLC staging system provides an easy-to-use algorithm that links tumour stages with treatment allocation policies based on evidence $[1,34]$. BCLC stage B is indicated to TACE, the standard of care with a median survival of 26 months for intermediate HCC [35], while sorafenib represents the first line treatment with a median survival of 6.5 months in HCC patients with BCLC stage C, the advanced HCC [36]. However, a growing body of evidence supports the use of TACE for patients with early and advanced HCC $[37,38]$ because of the tumour heterogeneity with more important therapeutic implications. Even if portal invasion is demonstrated, it is not the absolute contraindication of TACE [39]. The applications of surgical resection plus TACE and surgical resection plus sorafenib were the alternative strategies for BCLC stages B and C [7]. Therefore, patients with either BCLC stage $\mathrm{B}$ or $\mathrm{C}$ were mixed into two groups of this study. More advanced $\mathrm{HCC}$ in both groups resulted in lower median overall survival (7.5 months in TACE group and 15 months in TACE $+\mathrm{C}+\mathrm{L}$ group). With stratified 
evaluation, the median overall survival and DCR at 12 months of patients with BCLC stage $\mathrm{C}$ in TACE $+\mathrm{C}+\mathrm{L}$ group were significantly higher than those in TACE group, suggesting that the protocol of TACE $+\mathrm{C}+\mathrm{L}$ may be an alternative strategy for the patients with advanced HCC.

PES is a common complication caused by intrahepatic and extrahepatic inflammation due to tumor ischemia. By means of their anti-inflammatory characteristics, celecoxib+lanreotide significantly reduced the occurrence of PES with ORs of $0.011(p<0.001)$. It would be beneficial especially for aged patients due to ORs of age being $3.250(p=0.002)$. Although the symptoms of PES are usually self-limited, the severe complication may drive the cirrhotic stage into worse one and even liver failure [40]. The $43.3 \%$ reduction of PES in TACE $+\mathrm{C}+\mathrm{L}$ regimen would be positive for TACE compliance of $\mathrm{HCC}$ patients, which in turn endued more opportunities to undergo TACE sessions and improved DCR.

More mild abdominal bloating was complained in TACE group probably due to untreated PES. Other adverse events of the two groups may be partly or temporally related to TACE or celecoxib and lanreotide. The adverse events during long term administration of celecoxib and lanreotide are an issue of concern. Fortunately, the adverse events in $\mathrm{TACE}+\mathrm{C}+\mathrm{L}$ regimen were not more than those of TACE alone and no special adverse events were associated with celecoxib and lanreotide. All of patients in $\mathrm{TACE}+\mathrm{C}+\mathrm{L}$ group completed the follow-up with good compliance. Compared to sorafenib treatment, the dermatological reactions, fatigue, diarrhea, and arterial hypertension associated with sorafenib usually compel dose reduction or interruption of treatment [41].

This study has several limitations. Firstly, this is a study conducted in a single center. Secondly, this study is neither single- nor double-blinded which might introduce bias. A well-designed multiple centers RCTs are necessary to control the bias and afford better evidence.

In conclusion, the novel regimen of TACE with adjuvant celecoxib and lanreotide prolonged overall survival, enhanced tumour response, reduced PES and was well-tolerable in the patients with unresectable HCC. It may be more beneficial for the patients with advanced HCC.

\section{CONFLICTS OF INTEREST}

The authors declare no conflict of interest with respect to this manuscript.

\section{FINANCIAL SUPPORT}

This work was supported by the National Natural Science Fund of China (Grant No. 81670551) and the Supporting Project of Science and Techonology Department of Sichuan Province (Grant No. 2016SZ0041).

\section{REFERENCES}

1. European Association for the Study of the Liver and European Organisation for Research and Treatment of Cancer. EASL-EORTC Clinical Practice Guidelines: Management of hepatocellular carcinoma. J Hepatol. 2012; 56:908-943.

2. Llovet JM, Zucman-Rossi J, Pikarsky E, Sangro B, Schwartz M, Sherman M, Gores G. Hepatocellular carcinoma. Nature reviews Disease primers. 2016; 2:16018.

3. Fernandez M, Semela D, Bruix J, Colle I, Pinzani M, Bosch J. Angiogenesis in liver disease. J Hepatol. 2009; 50:604620 .

4. Wang B, Xu H, Gao ZQ, Ning HF, Sun YQ, Cao GW. Increased expression of vascular endothelial growth factor in hepatocellular carcinoma after transcatheter arterial chemoembolization. Acta Radiol. 2008; 49:523-529.

5. Lencioni R, Llovet JM, Han G, Tak WY, Yang J, Guglielmi A, Paik SW, Reig M, Kim do Y, Chau GY, Luca A, del Arbol LR, Leberre MA, et al. Sorafenib or placebo plus TACE with doxorubicin-eluting beads for intermediate stage HCC: The SPACE trial. J Hepatol. 2016; 64:10901098.

6. Pinter M, Ulbrich G, Sieghart W, Kolblinger C, Reiberger T, Li S, Ferlitsch A, Muller C, Lammer J, PeckRadosavljevic M. Hepatocellular Carcinoma: A Phase II Randomized Controlled Double-Blind Trial of Transarterial Chemoembolization in Combination with Biweekly Intravenous Administration of Bevacizumab or a Placebo. Radiology. 2015; 277:903-912.

7. Chang L, Wang Y, Zhang J, Guo T. The best strategy for HCC patients at each BCLC stage: a network meta-analysis of observational studies. Oncotarget. 2017; 8:20418-20427. doi: 10.18632/oncotarget.14668.

8. Wu T. Cyclooxygenase-2 in hepatocellular carcinoma. Cancer Treat Rev. 2006; 32:28-44.

9. Sui W, Zhang Y, Wang Z, Wang Z, Jia Q, Wu L, Zhang W. Antitumor effect of a selective COX-2 inhibitor, celecoxib, may be attributed to angiogenesis inhibition through modulating the PTEN/PI3K/Akt/HIF-1 pathway in an $\mathrm{H} 22$ murine hepatocarcinoma model. Oncol Rep. 2014; 31:22522260 .

10. Yin J, Liu B, Li B, Liu Z, Xie X, Lv Z, Gao S, Guang J. The cyclooxygenase-2 inhibitor celecoxib attenuates hepatocellular carcinoma growth and c-Met expression in an orthotopic mouse model. Oncol Res. 2011; 19:131-139.

11. Bassiouny AR, Zaky A, Neenaa HM. Synergistic effect of celecoxib on 5-fluorouracil-induced apoptosis in hepatocellular carcinoma patients. Ann Hepatol. 2010; 9:410-418.

12. Blaker M, Schmitz M, Gocht A, Burghardt S, Schulz M, Broring DC, Pace A, Greten H, de Weerth A. Differential expression of somatostatin receptor subtypes in hepatocellular carcinomas. J Hepatol. 2004; 41:112-118. 
13. Verhoef C, van Dekken H, Hofland LJ, Zondervan PE, de Wilt JH, van Marion R, de Man RA, JN IJ, van Eijck CH. Somatostatin receptor in human hepatocellular carcinomas: biological, patient and tumor characteristics. Digestive surgery. 2008; 25:21-26.

14. Xie Y, Chen S, Wang CH,Tang CW. [Induction of necrosis in the hepatocellular carcinoma HepG2 xenografts treated with SOM230]. Chung Hua Kan Tsang Ping Tsa Chih. 2009; 17:759-764.

15. Xie Y, Chen S, Wang C, Tang C. SOM230 combined with celecoxib prolongs survival in nude mice with HepG-2 xenografts. Cancer Biol Ther. 2011; 12:86-92.

16. Tong H, Li X, Zhang CL, Gao JH, Wen SL, Huang ZY, Tang CW. Octreotide and celecoxib synergistically encapsulate VX2 hepatic allografts following transcatheter arterial embolisation. Exp Ther Med. 2013; 5:777-782.

17. Tong $\mathrm{H}$, Li X, Zhang CL, Gao JH, Wen SL, Huang ZY, Wen FQ, Fu P, Tang CW. Transcatheter Arterial Embolization Followed by Octreotide and Celecoxib Synergistically Prolongs Survival of Rabbits with Hepatic VX2 Allografts. J Dig Dis. 2013; 14:29-37.

18. Llovet JM, Bru C, Bruix J. Prognosis of hepatocellular carcinoma: the BCLC staging classification. Semin Liver Dis. 1999; 19:329-338.

19. Lencioni R, Llovet JM. Modified RECIST (mRECIST) assessment for hepatocellular carcinoma. Semin Liver Dis. 2010; 30:52-60.

20. Trotti A, Colevas AD, Setser A, Rusch V, Jaques D, Budach V, Langer C, Murphy B, Cumberlin R, Coleman CN, Rubin P. CTCAE v3.0: Development of a comprehensive grading system for the adverse effects of cancer treatment. Semin Radiat Oncol. 2003; 13:176-181.

21. Mejias M, Garcia-Pras E, Tiani C, Bosch J, Fernandez M. The somatostatin analogue octreotide inhibits angiogenesis in the earliest, but not in advanced, stages of portal hypertension in rats. Journal of cellular and molecular medicine. 2008; 12:1690-1699.

22. Wang R, Guo L, Wang P, Yang W, Lu Y, Huang Z, Tang C. Chemoprevention of cancers in gastrointestinal tract with cyclooxygenase 2 inhibitors. Current pharmaceutical design. 2013; 19:115-125.

23. Gao JH, Wen SL, Feng S, Yang WJ, Lu YY, Tong H, Liu R, Tang SH, Huang ZY, Tang YM, Yang JH, Xie HQ, Tang CW. Celecoxib and octreotide synergistically ameliorate portal hypertension via inhibition of angiogenesis in cirrhotic rats. Angiogenesis. 2016; 19:501-511.

24. Wang LJ, Bai L, Su D, Zhang T, Mao ZY. Proinflammatory conditions promote hepatocellular carcinoma onset and progression via activation of Wnt and EGFR signaling pathways. Mol Cell Biochem. 2013; 381:173-181.

25. Gao JH, Wen SL, Tong H, Wang CH, Yang WJ, Tang SH, Yan ZP, Tai Y, Ye C, Liu R, Huang ZY, Tang YM, Yang $\mathrm{JH}$, et al. Inhibition of cyclooxygenase-2 alleviates liver cirrhosis via improvement of the dysfunctional gut-liver axis in rats. Am J Physiol Gastrointest Liver Physiol. 2016; 310:G962-972.

26. Gao JH, Wen SL, Yang WJ, Lu YY, Tong H, Huang ZY, Liu ZX, Tang CW. Celecoxib ameliorates portal hypertension of the cirrhotic rats through the dual inhibitory effects on the intrahepatic fibrosis and angiogenesis. PLoS One. 2013; 8:e69309.

27. Wen SL, Gao JH, Yang WJ, Lu YY, Tong H, Huang ZY, Liu ZX, Tang CW. Celecoxib attenuates hepatic cirrhosis through inhibition of epithelial-to-mesenchymal transition of hepatocytes. J Gastroenterol Hepatol. 2014; 29:19321942.

28. Sola E, Gines P. Renal and circulatory dysfunction in cirrhosis: current management and future perspectives. $\mathrm{J}$ Hepatol. 2010; 53:1135-1145.

29. Oberg K, Lamberts SW. Somatostatin analogues in acromegaly and gastroenteropancreatic neuroendocrine tumours: past, present and future. Endocr Relat Cancer. 2016; 23:R551-R566.

30. Raderer M, Hejna MH, Muller C, Kornek GV, Kurtaran A, Virgolini I, Fiebieger W, Hamilton G, Scheithauer W. Treatment of hepatocellular cancer with the long acting somatostatin analog lanreotide in vitro and in vivo. Int $\mathrm{J}$ Oncol. 2000; 16:1197-1201.

31. Raderer M, Hejna MH, Kurtaran A, Kornek GV, Valencak JB, Oberhuber G, Vorbeck F, Virgolini I, Scheithauer W. Successful treatment of an advanced hepatocellular carcinoma with the long-acting somatostatin analog lanreotide. Am J Gastroenterol. 1999; 94:278-279.

32. Waser B, Tamma ML, Cescato R, Maecke HR, Reubi JC. Highly efficient in vivo agonist-induced internalization of sst2 receptors in somatostatin target tissues. Journal of nuclear medicine : official publication, Society of Nuclear Medicine. 2009; 50:936-941.

33. Boudin H, Sarret P, Mazella J, Schonbrunn A, Beaudet A. Somatostatin-induced regulation of $\operatorname{SST}(2 \mathrm{~A})$ receptor expression and cellsurface availability in central neurons: role of receptor internalization. The Journal of neuroscience. 2000; 20:5932-5939.

34. Bruix J, Han KH, Gores G, Llovet JM, Mazzaferro V. Liver cancer: Approaching a personalized care. J Hepatol. 2015; 62:S144-156.

35. Kudo M, Han G, Finn RS, Poon RT, Blanc JF, Yan L, Yang J, Lu L, Tak WY, Yu X, Lee JH, Lin SM, Wu $\mathrm{C}$, et al. Brivanib as adjuvant therapy to transarterial chemoembolization in patients with hepatocellular carcinoma: A randomized phase III trial. Hepatology. 2014; 60:1697-1707.

36. Cheng AL, Kang YK, Chen Z, Tsao CJ, Qin S, Kim JS, Luo R, Feng J, Ye S, Yang TS, Xu J, Sun Y, Liang H, et al. Efficacy and safety of sorafenib in patients in the AsiaPacific region with advanced hepatocellular carcinoma: a phase III randomised, double-blind, placebo-controlled trial. Lancet Oncol. 2009; 10:25-34. 
37. Casadaban LC, Minocha J, Bui JT, Knuttinen MG, Ray CE Jr, Gaba RC. Conventional Ethiodized Oil Transarterial Chemoembolization for Treatment of Hepatocellular Carcinoma: Contemporary Single-Center Review of Clinical Outcomes. AJR Am J Roentgenol. 2016; 206:645654.

38. Kim HC, Suk KT, Kim DJ, Yoon JH, Kim YS, Baik GH, Kim JB, Kim CH, Sung H, Choi JY, Han KH, Park SH. Transarterial chemoembolization in Barcelona Clinic Liver Cancer Stage 0/A hepatocellular carcinoma. World J Gastroenterol. 2014; 20:745-754.

39. Raoul JL, Sangro B, Forner A, Mazzaferro V, Piscaglia F, Bolondi L, Lencioni R. Evolving strategies for the management of intermediate-stage hepatocellular carcinoma: available evidence and expert opinion on the use of transarterial chemoembolization. Cancer Treat Rev. 2011; 37:212-220.
40. Sun Z, Li G, Ai X, Luo B, Wen Y, Zhao Z, Dong S, Guan J. Hepatic and biliary damage after transarterial chemoembolization for malignant hepatic tumors: incidence, diagnosis, treatment, outcome and mechanism. Crit Rev Oncol Hematol. 2011; 79:164-174.

41. von Felden J, Schulze K, Gil-Ibanez I, Werner T, Wege H. First- and Second-Line Targeted Systemic Therapy in Hepatocellular Carcinoma-An Update on Patient Selection and Response Evaluation. Diagnostics. 2016; 6. 